\title{
Gene expression patterns in the histopathological classification of epithelial ovarian cancer
}

\author{
HONGLAN ZHU ${ }^{1,2}$ and JING JIE YU ${ }^{1}$ \\ ${ }^{1}$ Department of Biochemistry, School of Medicine, Department of Basic Pharmaceutical Sciences, \\ School of Pharmacy and Mary Babb Randolph Cancer Center, Robert C. Byrd Health Sciences Center, \\ West Virginia University, Morgantown, WV 26506, USA; ${ }^{2}$ Department of Obstetrics and Gynecology, \\ Peking University People's Hospital, Beijing 100044, P.R. China
}

Received July 27, 2009; Accepted October 5, 2009

DOI: 10.3892/etm_00000030

\begin{abstract}
The purpose of this study was to screen cancerrelated genes and to identify histopathological gene expression patterns as potential biomarkers in human epithelial ovarian cancer (EOC). Fifty genes were screened by reversetranscription polymerase chain reaction assay with cDNA from 83 EOC tissues and 48 normal ovarian specimens of ovarian cancer patients and evaluated by gel electrophoresis analysis. Twenty expressed genes were assessed by real-time relativequantity (RQ)-PCR in 30 EOC specimens for gene signature study. Four genes, TAL2, EGF, ILF3 and UBE2I, were investigated for gene expression patterns in histopathological classification of EOC. RQ-value ( $\mathrm{Ct}, \Delta \mathrm{Ct}, \Delta \Delta \mathrm{Ct}$, RQ and gene expression plots) was generated by ABI 7500 Fast System SDS Software (version 1.4). SPSS 15.0 software was used for statistical analysis. Using real-time RQ-PCR, we found that TAL2, EGF, ILF3 and UBE2I demonstrated distinct expression patterns in histological types of epithelial ovarian cancer. The expression of ILF3 and UBE2I in tumors was significantly higher than in normal tissue, with extremely high expression in serous carcinomas compared to mucinous, endometrium and clear cell carcinomas. In addition, ILF3 and UBE2I were overexpressed in advanced stage and advanced grade ovarian cancer, compared to early stage or well-differentiated ovarian cancer. This is the first report of TAL2 and ILF3 expression in the normal human ovary and epithelial ovarian cancer. Our results indicate that overexpression of ILF3 and UBE2I in advanced stage and advanced grade suggest that these two
\end{abstract}

Correspondence to: Dr Jing Jie Yu, Department of Biochemistry, School of Medicine, Department of Basic Pharmaceutical Sciences, School of Pharmacy and Mary Babb Randolph Cancer Center, Robert C. Byrd Health Sciences Center, West Virginia University, Morgantown, WV 26506, USA

E-mail: jyu@hsc.wvu.edu

Key words: gene signature, histopathological types, epithelial ovarian cancer, real-time quantitative PCR genes may play an important role in tumorigenesis/tumor progression and pathological differentiation of the disease. Notably, ILF3 plays a role in DNA binding activity and transcriptional and post-transcriptional regulation; UBE2I is required in ubiquitination and sumoylation and is involved in DNA repair and apoptosis of cells. Further investigations to reveal the molecular mechanisms related to the activation of $I L F 3$ and UBE2I in the development of EOC are warranted.

\section{Introduction}

Surface epithelial carcinomas are the most common type of ovarian cancer and the most lethal gynecological malignancy. Epithelial ovarian cancer (EOC) comprises the majority of malignant ovarian tumors in adult women, and its high mortality is mainly due to late diagnosis (1). Serous epithelial carcinoma, the primary type of ovarian cancer, usually presents at advanced stage. Endometrioid, mucinous and clear-cell carcinomas, accounting for non-serous carcinomas, more often appear as low-stage disease $(1,2)$. In advanced stages, the response rate to first-line chemotherapy with a platinum combination after surgical resection is approximately $80 \%$, with $40-60 \%$ complete response. However, the median progression-free survival is only 18 months in these patients, as most relapse. The overall response rate in platinum-refractory or drug-resistant tumors is only $10-25 \%$ with subsequent relapse, resulting in a 5-year survival of only $25 \%$ (3). In addition, clinicians have long known that different subtypes of ovarian cancer respond differently to treatment and have different prognoses. High-grade serous ovarian cancers typically harbor mutations in p53. These cancers also have mutations of BRCA1 or BRCA2, as well as defective homologous recombination, the preferred mechanism of the DNA double-strand break repair pathway $(3,4)$. EOC, a morphologically and biologically heterogeneous disease, is affected by various gene activations and alterations (2-5).

Current studies suggest that the different histological types of EOC represent distinct disease entities and exhibit varied gene expression patterns $(6,7)$. Thus, a better understanding of the molecular basis of EOC subtypes and identification of a reliable gene expression profile for each type is necessary to uncover the fundamental mechanisms of carcinogenesis and 
Table I. Primer sequences of the 4 targeted genes used in real-time quantitative PCR.

\begin{tabular}{lccc}
\hline Gene symbol & Gene ID & Forward primer & Reverse primer \\
\hline$T A L 2$ & 6887 & 5'-tcacctccagacaaaaagc-3' & 5'-ccaggtgaaggaacctggta-3' \\
$E G F$ & 1950 & 5'-aggtggctggaagcctttat-3' & 5'-tgtggacagaacctccatca-3' \\
$I L F 3$ & 3609 & 5'-ctggtgctgctgtgtaagga-3' & 5'-agggacaatggaggctctt-3' \\
UBE2I & 7329 & 5'-caggagaggaaagcatggag-3' & 5'-tcgggtgaaataatggtggt-3' \\
\hline
\end{tabular}

to predict prognosis, and may provide therapeutic guidance in these diseases (8).

DNA microarray research is widely applied in determining gene expression profiles and has opened the field for analysis of the expression levels of thousands of genes (9). However, a more accurate technique is needed for a better-tailored approach to identify special targets of diagnostic and prognostic markers that predict patient response to chemotherapy and survival outcomes. We used real-time relative-quantity (RQ)-PCR assay to illustrate a gene expression signature and to distinguish expression patterns in EOC subtypes in a large patient sample panel. Based on the function of targeted genes and their expression patterns, we identified ILF3 and UBE2I as potential biomarkers for this disease.

\section{Materials and methods}

Human tissue specimens. Forty-eight pairs of ovarian specimens (tumor and adjacent normal tissues), plus an additional 35 tumors from a total of 83 patients with advanced ovarian cancer were obtained from the Cooperative Human Tissue Network (CHTN), Pediatric Division, Children's Hospital, Columbus, OH, USA. Tumor and normal samples were collected at primary surgery prior to chemotherapy, flash frozen in liquid nitrogen, and stored at $-80^{\circ} \mathrm{C}$ until RNA/ DNA extraction. All samples were evaluated by pathologists, and the 83 tumors were classified as serous carcinoma $(n=51)$, endometrioid carcinoma $(n=13)$, mucinous carcinoma $(n=11)$ and clear cell carcinoma $(n=8)$.

RNA extraction. Total RNA from each specimen and the normal control of the ovarian cancer patients was extracted and purified by the method of hot phenol/chloroform extraction as previously reported (10). Isolated RNA was purified and dissolved in DEPC water and stored at $-80^{\circ} \mathrm{C}$.

Oligo synthesis. Following a search of the gene database, we selected a total of 50 genes based on their functions and the expression literature in ovarian, breast and lung cancers for this investigation. Primary gene functions included transcription factor, DNA/RNA and protein binding activity, gene activation and regulation. Forward and reverse primers for each of the 50 genes were synthesized by Gene Probe Technologies, Inc. (Gaithersburg, MD, USA). Primer sequences of the 4 targeted genes used in real-time quantitative PCR assay are listed in Table I.

Reverse transcription-PCR. Through reverse transcription (RT), using the Super Script Preamplification System (Life
Technologies, Inc.), cDNA was generated with oligo-dT primers from $5 \mu \mathrm{g}$ of total RNA of 83 ovarian tumor tissues and 48 adjacent normal samples. RT-PCR was performed using AmpliTaq DNA polymerase, FS cells and gene-specific primers of the 50 genes in all cDNA samples. PCR amplicons were separated by $1 \%$ agarose gel electrophoresis, and visible density bands of the gene amplification in these samples were indicative of gene expression. Genes expressed in RT-PCR detection were selected for subsequent real-time quantitative PCR analysis.

Real-time quantitative PCR. Real-time RQ-PCR was performed using $S Y B{ }^{\circledR}$ Green reagent kit (ABI Cat. 4367659) according to manufacturer's recommendations. This assay was used for 20 selected genes in 30 EOC specimens for the gene expression signature profile. Amplifications were carried out on ABI PRISM 7000 Detection System and analyzed by ABI 7500 software (PE Applied Biosystems, Foster City, CA, USA).

In brief, all reactions were optimized to obtain the best amplification kinetics under the same cycling conditions $\left(10 \mathrm{~min}\right.$ at $95^{\circ} \mathrm{C}, 40$ cycles of $15 \mathrm{sec}$ at $95^{\circ} \mathrm{C}$, and 1-min at $60^{\circ} \mathrm{C}$ ). The composition of the reaction mixture in a final volume of $20 \mu \mathrm{l}$ contained Power SYBR Green Master Mix $10 \mu \mathrm{l}$, gene-specific primers $(10 \mu \mathrm{M}) 1 \mu \mathrm{l}$ and cDNA $2 \mu \mathrm{l}$. Negative controls containing all PCR components without template DNA (denoted NTC) were used to ensure that the reagent mix was free of contamination. Each reaction was run in triplicate. The average threshold cycle $(\mathrm{Ct})$ and the comparative $\Delta \Delta \mathrm{Ct}$ method were automatically calculated for the expression of the gene and normalized to the mean Ct-value of $18 \mathrm{~S}$ ribosomal. The RQ-value was calculated using the $\Delta \Delta \mathrm{Ct}$ method. Fold change in gene expression was calculated as $2^{-\Delta \Delta \mathrm{Ct}}$. For each gene in this study, a Ct-value $<32$ was considered as positive expression and vice versa.

Statistical analysis. In real-time RQ-PCR assays, the average $\mathrm{Ct}, \Delta \mathrm{Ct}, \Delta \Delta \mathrm{Ct}$ and RQ were calculated by Applied Biosystems Sequence detection software (7500 Fast System SDS Software version 1.4). RQ ( $\Delta \Delta \mathrm{Ct}$ value) was used to compare gene expression between samples. Since RQ equals $2^{-\Delta \Delta C t}$, a higher negative $\Delta \Delta \mathrm{Ct}$ value, represents higher expression. SPSS 15.0 software was used to determine statistical significance. A P-value $<0.05$ was considered statistically significant between test means.

\section{Results}

Patient characteristics. Forty-eight pairs of ovarian specimens (tumor and adjacent normal tissues) plus an additional 
Table II. Clinicopathological characteristics of the EOC cases.

\begin{tabular}{|c|c|c|c|c|c|c|c|c|c|}
\hline \multirow{2}{*}{$\begin{array}{l}\text { Patient } \\
\text { no. }\end{array}$} & \multirow{2}{*}{$\begin{array}{l}\text { Age range } \\
\text { (years) }\end{array}$} & \multirow{2}{*}{$\begin{array}{l}\text { Histological } \\
\text { type }\end{array}$} & \multicolumn{4}{|c|}{ FIGO stage at diagnosis } & \multicolumn{3}{|c|}{ Tumor grade } \\
\hline & & & I & II & III & IV & G1 & G2 & G3 \\
\hline 51 & $40-83$ & Serious & $\begin{array}{c}3 \\
(5.88 \%)\end{array}$ & $\begin{array}{c}2 \\
(3.92 \%)\end{array}$ & $\begin{array}{c}42 \\
(82.35 \%)\end{array}$ & $\begin{array}{c}4 \\
(7.84 \%)\end{array}$ & $\begin{array}{c}3 \\
(5.88 \%)\end{array}$ & $\begin{array}{c}9 \\
(17.65 \%)\end{array}$ & $\begin{array}{c}39 \\
(76.47 \%)\end{array}$ \\
\hline 11 & $40-74$ & Mucinous & $\begin{array}{c}7 \\
(63.64 \%)\end{array}$ & $\begin{array}{c}3 \\
(27.27 \%)\end{array}$ & $\begin{array}{c}1 \\
(9.09 \%)\end{array}$ & 0 & $\begin{array}{c}5 \\
(45.45 \%)\end{array}$ & $\begin{array}{c}4 \\
(36.36 \%)\end{array}$ & $\begin{array}{c}2 \\
(18.18 \%)\end{array}$ \\
\hline 13 & $37-76$ & Endometrioid & $\begin{array}{c}4 \\
(30.77 \%)\end{array}$ & $\begin{array}{c}3 \\
(7.69 \%)\end{array}$ & $\begin{array}{c}6 \\
(46.15 \%)\end{array}$ & 0 & $\begin{array}{c}2 \\
(15.38 \%)\end{array}$ & $\begin{array}{c}4 \\
(30.77 \%)\end{array}$ & $\begin{array}{c}7 \\
(53.85 \%)\end{array}$ \\
\hline 8 & $48-77$ & Clear cell & $\begin{array}{c}6 \\
(75 \%)\end{array}$ & $\begin{array}{c}1 \\
(12.50 \%)\end{array}$ & $\begin{array}{c}1 \\
(12.50 \%)\end{array}$ & 0 & $\begin{array}{c}3 \\
(37.50 \%)\end{array}$ & $\begin{array}{c}1 \\
(12.50 \%)\end{array}$ & $\begin{array}{c}4 \\
(50 \%)\end{array}$ \\
\hline
\end{tabular}

FIGO, International Federation of Gynecology and Obstetrics.

Table III. Function of 20 dominant and reproducible genes expressed in the studied ovarian specimens.

\begin{tabular}{|c|c|c|}
\hline Gene symbol & Gene name & Function \\
\hline RAD52 & RAD52 homolog (S. cerevisiae) & $\begin{array}{l}\text { DNA double-strand break repair and } \\
\text { homologous recombination }\end{array}$ \\
\hline RPUSD2 & $\begin{array}{l}\text { RNA pseudouridylate synthase domain } \\
\text { containing } 2\end{array}$ & Pseudouridine synthase activity \\
\hline SEHIL & SEH1-like (S. cerevisiae) & Intracellular protein transport across a membrane \\
\hline SLC25A5 & Solute carrier familly 25 member 5 & Adenine transmembrane transporter \\
\hline PLSCR1 & Phospholipid scramblase 1 & Phospholipid scramblase activity \\
\hline INPPLI & Inositol polyphosphate phosphatase-like 1 & Inositol or phosphatidylinositol phosphatase activity \\
\hline TXNRD1 & Thioredoxin reductase 1 & $\begin{array}{l}\text { Protein disulfide oxidoreductase activity, } \\
\text { thioredoxin-disulfide reductase activity }\end{array}$ \\
\hline$S S B P 1$ & Single-stranded DNA binding protein 1 & Housekeeping gene involved in mitochondrial biogenesis \\
\hline FAT & $\begin{array}{l}\text { Fat tumor suppressor homolog } 1 \\
(\text { Drosophila) }\end{array}$ & Calcium ion binding, protein binding \\
\hline SMARCD2 & $\begin{array}{l}\text { SWI/SNF-related, matrix-associated, } \\
\text { actin-dependent regulator of chromatin, } \\
\text { subfamily d, member } 2\end{array}$ & Transcription coactivator activity protein binding \\
\hline$M A P 2 K 2$ & Mitogen-activated protein kinase 2 & $\begin{array}{l}\text { Protein serine/threonine kinase activity, } \\
\text { protein tyrosine kinase activity, transferase activity }\end{array}$ \\
\hline HNRNPA3 & Heterogeneous nuclear ribonucleoprotein A3 & Nuclear mRNA splicing, via spliceosome \\
\hline$M S X 2$ & msh homeobox 2 & Transcription factor activity \\
\hline$T A L 2$ & T-cell acute lymphocytic leukemia 2 & Transcription regulator activity \\
\hline$E G F$ & Epidermal growth factor & $\begin{array}{l}\text { Epidermal growth factor receptor activating } \\
\text { ligand activity, calcium ion binding }\end{array}$ \\
\hline ZNF71 & Zinc finger protein 71 & Metal ion binding, zinc ion binding \\
\hline ILF3 & Interleukin enhancer binding factor 3 & Double-stranded RNA binding, transcription regulation \\
\hline$U B E 2 I$ & $\begin{array}{l}\text { Ubiquitin-conjugating enzyme E2I } \\
\text { (UBC9 homolog, yeast) }\end{array}$ & $\begin{array}{l}\text { Post-translational protein modification, ubiquitin-dependent } \\
\text { protein catabolic process }\end{array}$ \\
\hline INSR & Insulin receptor & $\begin{array}{l}\text { Insulin receptor activity, phosphoinositide } 3 \text {-kinase binding } \\
\text { receptor signaling protein tyrosine kinase activity }\end{array}$ \\
\hline NP220 & Zinc finger protein 638 & $\begin{array}{l}\text { Double-stranded DNA binding, metal ion binding, } \\
\text { zinc ion binding }\end{array}$ \\
\hline
\end{tabular}


Table IV. Comparison of the rate of expression between tumor and normal samples (Chi-square test).

\begin{tabular}{lcccc}
\hline & TAL2 & EGF & ILF3 & UBE2I \\
\hline EOC tumors (83) & $96.4 \%(80 / 83)$ & $83.1 \%(69 / 83)$ & $85.5 \%(71 / 83)$ & $65.1 \%(54 / 83)$ \\
Normal samples (48) & $100.0 \%(48 / 48)$ & $93.8 \%(45 / 48)$ & $58.3 \%(28 / 48)$ & $25.0 \%(12 / 48)$ \\
P-value & 0.468 & 0.081 & $<\mathbf{0 . 0 5}$ & $<\mathbf{0 . 0 5}$ \\
\hline
\end{tabular}

35 tumors (from a total of 83 ovarian cancer patients) were assessed in this investigation. The clinicopathological characteristics of the 83 EOC patients in this study are shown in Table II. The median age of the patients at diagnosis was 59 years (range, $37-83$ years). Approximately $65.1 \%$ of the patients (54 out of 83) were diagnosed with advanced stage tumors (FIGO stages III/IV), and 84.3\% (70 out of 83) had moderately poorly differentiated tumors (grades 2 and 3 ).

Reproducible gene expression identified in the studied samples. Initially, we selected 50 genes based on their functions and the expression literature. Using reverse transcription-polymerase chain reaction assay (RT-PCR), 39 of the 50 genes were expressed by showing gel electrophoresis density; the remaining 11 genes were not expressed (data not shown). Of the 39 expressed genes, 20 demonstrated dominant and reproducible expression among the samples. These 20 genes were further evaluated in 30 EOC specimens by real-time quantitative PCR. The functions of these 20 genes are summarized in Table III.

Expression patterns of TAL2, EGF, ILF3 and UBE2I in normal and EOC specimens. Using real-time RQ-PCR we further identified four genes (TAL2, EGF, ILF3 and UBE2I) among the 20 selected genes for extensive study. These genes demonstrated distinct expression patterns among the EOC subtypes. In brief, TAL2 was expressed in 80 of the 83 EOC and all 48 normal samples. $E G F$ was expressed in 69 of the 83 EOC and 45 of the 48 normal samples. Seventy-one of the 83 EOC samples exhibited ILF3 expression, and 54 of the 83 EOC exhibited UBE2I expression. In comparison, ILF3 was expressed in 28 of the 48 and $U B E 2 I$ was expressed in 12 of the 48 normal samples. The differences in $I L F 3$ and $U B E 2 I$ expression between the tumor and normal tissues were statistically significant $(\mathrm{P}<0.05)$ (Table IV). As shown in Fig. 1, 4 genes were expressed in all types of EOC and normal tissues. However, ILF3 expression in EOC was 4.8-fold higher than in the normal samples; UBE2I expression in EOC was $>2$-fold higher compared to that of the normal samples.

The expression patterns of TAL2, EGF, ILF3 and UBE2I in the histological types of EOC. Fig. 2 shows the mean RQ-value of TAL2, EGF, ILF3 and UBE2I in histological types of EOC. $T A L 2, E G F, I L F 3$ and $U B E 2 I$ were expressed in all EOC subtypes. Interestingly, the mean RQ value of $I L F 3$ in the serous patients was 2.671 compared to 0.6 in clear cell, 0.256 in endometrioid and 0.336 in mucinous carcinomas. The mean RQ value of $U B E 21$ in serous patients was 4.979 compared to 0.224 in clear cell, 0.243 in endometrioid and 0.46 in mucinous carcinomas. In other words, ILF3 and UBE2I showed extremely high expression in serous carcinomas.

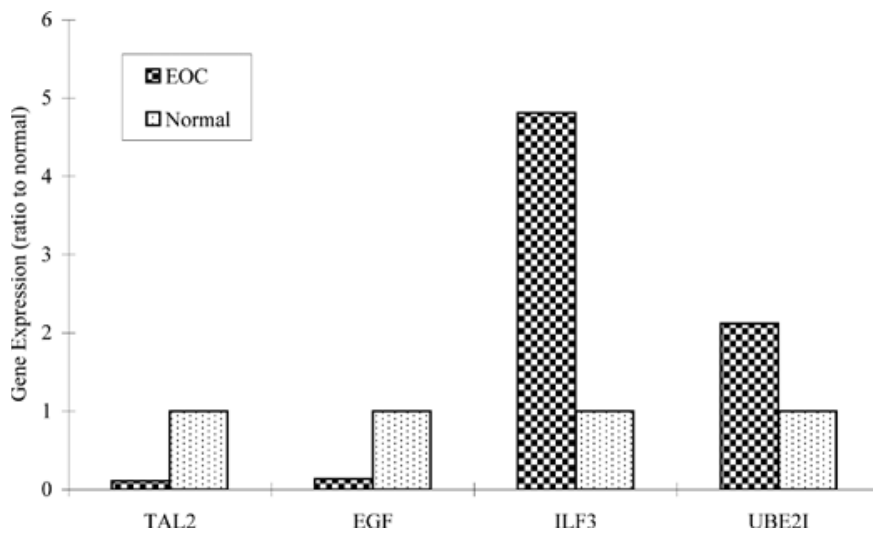

Figure 1. Expression patterns of TAL2, EGF, ILF3 and $U B E 2 I$ in normal and tumor tissues. The mean RQ-value of TAL2 in EOC (0.344) vs. the value in normal sample (3.118) was 0.11. The mean RQ-value of EGF in EOC (0.426) vs. the value in normal samples (3.174) was 0.134. The mean RQ-value of ILF3 in EOC (1.968) vs. the value in normal sample (0.409) was 4.812 $(\mathrm{P}<0.05)$. The mean RQ-value of $U B E 2 I$ in EOC (3.757) vs. the value in normal sample (1.771) was $2.121(\mathrm{P}<0.05)$.

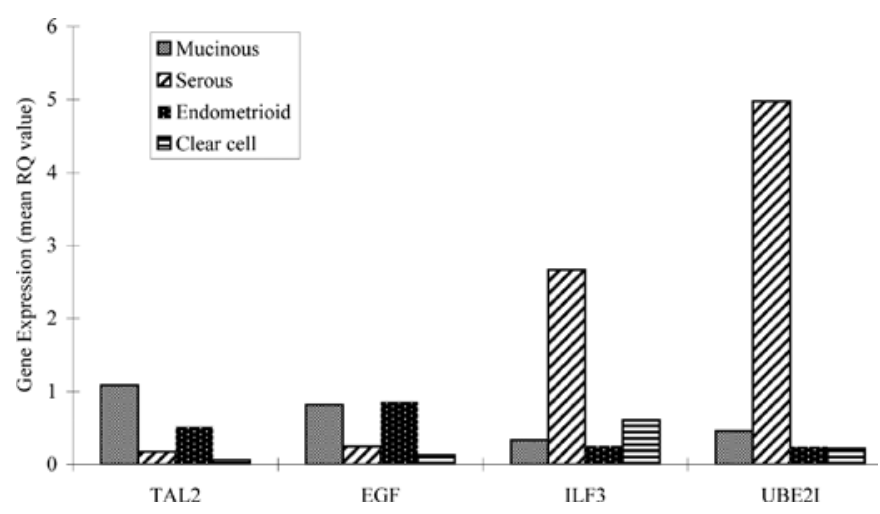

Figure 2. Expression patterns of TAL2, EGF, ILF3 and UBE2I in histological types of EOC samples. ILF3 and UBE2I showed extremely high expression in serous carcinomas. The mean RQ-value of $I L F 3$ in serous patients was 2.671 compared to 0.6 in clear cell, 0.256 in endometrioid and 0.336 in mucinous carcinomas. The mean RQ-value of UBE2I in serous patients was 4.979 compared to 0.224 in clear cell, 0.243 in endometrioid and 0.46 in mucinous carcinomas.

Association of expression patterns with FIGO stage and tumor grade. The expression patterns of TAL2, EGF, ILF3 and $U B E 2 I$ were correlated with FIGO stage and tumor grade among 83 EOC tissues using real-time quantitative PCR analysis (Table V). The mean RQ-values of TAL2 and EGF in early stage or low grade and in advanced disease were overall low. In contrast, the mean RQ for ILF3 in advanced stage 
Table V. Association of expression patterns with FIGO stage and tumor grade.

\begin{tabular}{llllc}
\hline Mean RQ-value & TAL2 & $E G F$ & ILF3 & UBE2I \\
\hline Early stage (I-II) & 0.424 & 0.514 & 0.671 & 0.864 \\
Advanced stage (III-IV) & 0.301 & 0.402 & 2.550 & 4.975 \\
Advanced stage vs. early stage (fold) & 0.710 & 0.782 & $\mathbf{3 . 8 0 0}$ & $\mathbf{5 . 7 5 8}$ \\
G1 & 0.517 & 0.582 & 0.241 & 0.885 \\
G2-G3 & 0.310 & 0.400 & 2.251 & 3.406 \\
G2-G3 vs. G1 (fold) & 0.600 & 0.687 & $\mathbf{9 . 3 4 0}$ & $\mathbf{3 . 8 4 9}$ \\
\hline
\end{tabular}

vs. early stage was 3.8 ; in poorly differentiated $(\mathrm{G} 2 / \mathrm{G} 3)$ vs. well-differentiated (G1) this value was 9.34; for $U B E 2 I$, the RQ-value was 5.76 and 3.85. The overexpression of ILF3 and UBE2I in advanced stage and advanced grade indicates that these two genes may play an important role in tumor progression and pathological differentiation of this disease.

\section{Discussion}

$T A L 2$, one of three transcription factors of the basic helixloop-helix (bHLH) family, was found at junctions of chromosomal translocations associated with T-cell acute lymphoblastic leukaemia (T-ALL). This gene was activated in the chromosomal translocation $\mathrm{t}(7 ; 9)$ (q35;q34) in a subset of T-ALL patients causing overexpression in the T-cell lineage $(11,12)$. Thus, $T A L 2$ is identified as an oncogenic transcription factor of T-ALL (13). TAL2 expression in adult testes represents the gene's role in the developing midbrain, diencephalon and anterior pons (11). Bucher et al reported that TAL2 normally plays a pivotal role in brain development, and that without this gene, mice cannot survive to maturity (12). In the present study, we report, for the first time, TAL2 expression in normal human ovarian and ovarian tumor tissues.

Epidermal growth factor $(E G F)$ has a profound effect on the differentiation of ovarian surface epithelial cells by enhancing motility and inducing secretion of pro-MMP-2 and MMP-9 resulting in localized stimulation (14). EGF likely contributes to ovarian surface epithelium (OSE) rapid post-ovulatory proliferation and to the epithelio-mesenchymal conversion trapped in the ruptured follicle. Failure of such function may lead to the formation of epithelial inclusion cysts, which are known to be the preferential sites of malignant transformation by generating a microenvironment enriched of growth factors, cytokines and hormones to the entrapped OSE (15). There are a few reports regarding $E G F$ expression in tumors. Stromberg and colleagues reported that 10 of $10(100 \%)$ borderline tumors and 10 of $14(71 \%)$ epithelial ovarian tumors expressed EGF (16). Niikura et al also observed EGF expression in 18 of $25(72 \%)$ studied epithelial ovarian tumors (17). Our study of a large sample panel (83 ovarian patients) demonstrated that $E G F$ was expressed in both normal and the four histological tumor subtypes, which is consistent with other reports.

ILF3 (a protein known as NFAR or NF90), not previously found in ovarian cancer, was originally identified as a component of a dimeric transcription regulator and has a regulatory function in vitro. More recent studies suggest that
ILF3 plays a role in transcriptional and post-transcriptional regulation (18). NFAR or NF90 are ubiquitously expressed in the nucleus of many cell types and tissues. They interact with PKR and PKR-mediated signaling, and may be involved in the mRNA processing in cells (19). Vumbaca et al have demonstrated that the DRBP76/NF90 isoform facilitates the expression of vascular endothelial growth factor (VEGF) by promoting VEGF mRNA loading onto polysomes and translation under hypoxic conditions, thus promoting breast cancer growth and angiogenesis in vivo (20). VEGF, the key angiogenic factor expressed under restricted nutrient and oxygen conditions in most solid tumors, is up-regulated in ovarian tumors and promotes tumor cell growth, migration and survival $(21,22)$. Thus, ILF3 may play a role in tumorigenesis of EOC via regulation of VEGF expression. In our study, we observed that ILF3 was overexpressed in serous carcinoma. Serous carcinoma has the highest percentage of advanced stage and poorly differentiated cases among these four subtypes. We also found that ILF3 exhibited a higher expression trend in advanced stage or poorly differentiated EOC, compared to early stage or well-differentiated EOC.

UBE2I (Ubc9) is important for genome integrity, particularly during mitosis and overall cell survival (23). Recently, sumoylation, small ubiquitin-related modifier (SUMO) conjugation, has been identified as another type of protein modification. Ubc9, an essential E2-conjugating enzyme for sumoylation, seems to play a central role in sumoylation-mediated cellular pathways (24). In addition, several important DNA repair enzymes are subject to sumoylation, which appears to be involved in DNA damage/ repair. Moreover, Ubc9/SUMO are recently reported to have a fundamental effect in tumorigenesis and tumor progression $(23,25)$. Many oncoproteins and tumor supressors including PML, MDM2, c-MYB, c-JUN and TP53 are involved in SUMO (23-25). Our findings demonstrated that UBE2I mRNA was up-regulated in serous carcinoma of the ovary which is consistent with a report by Mo et al (24). The molecular mechanism by which Ubc9 promotes tumor growth and interacts with other factors is as yet unclear.

In conclusion, we provide the first evidence of TAL2 and $I L F 3$ expression in normal human ovary and epithelial ovarian cancer. We demonstrated that UBE2I and ILF3 expression was higher in advanced stage or poorly differentiated tumors, compared to early stage or well-differentiated EOC. Our results indicate that $I L F 3$ and $U B E 2 I$ may play an important role in tumorigenesis of EOC. Further investigations to 
elucidate the molecular mechanisms involved in ILF3 and $U B E 2 I$ activiation in EOC development are warranted.

\section{Acknowledgements}

This study was supported by NIH Grant RO3 CA107979-01 and the WVU Mary Babb Randolph Cancer Center, Molecular Medicine Core Facility, with editorial assistance by Michael D. Mueller.

\section{References}

1. Shih IM and Kurman RJ: Ovarian tumorigenesis. Am J Pathol 164: 1511-1518, 2004.

2. Baranova A, Gowder S, Naouar S, et al: Expression profile of ovarian tumors distinct signature of Sertoli-Leydig cell tumor. Int J Gynecol Cancer 16: 1963-1972, 2006.

3. Yu JJ: Unlocking the molecular mechanisms of DNA repair and platinum drug resistance in cancer chemotherapy. Curr Drug Ther 4: 19-28, 2009.

4. Bell DA: Origins and molecular pathology of ovarian cancer. Mod Pathol 18: 19-32, 2005.

5. Cecco LD, Marchionni L, Gariboldi M, et al: Gene expression profiling of advanced ovarian cancer characterization of a molecular signature involving fibroblast growth factor 2 . Oncogene 23: 8171-8183, 2004.

6. Tothill RW, Tinker AV, Joshy G, et al: Novel molecular subtypes of serous and endometrioid ovarian cancer linked to clinical outcome. Clin Cancer Res 14: 5198-5208, 2008.

7. Reed E, Yu JJ, Davies A, Gannon J and Armentrout SL: Clear cell tumors have higher mRNA levels of ERCC1 and XPB than other histological types of epithelial ovarian cancer. Clin Cancer Res 9: 5299-5305, 2003.

8. Schwartz DR, Kardia SLR, Shedden KA, et al: Gene expression in ovarian cancer reflects both morphology and biological behavior, distinguishing clear cell from other poor-prognosis ovarian carcinomas. Cancer Res 62: 4722-4729, 2002.

9. Fehrmann RS, Li XY, van Der Zee AG, de Jong S, Te Meerman GJ, de Vries EG and Crijns AP: Profiling studies in ovarian cancer: a review. The Oncologist 12: 960-966, 2007.

10. Yu JJ, Dabholkar M, Bennett WP, Welsh JA, Mu CJ, BostickBruton F and Reed E: Platinum-sensitive and platinum-resistant ovarian cancer tissues show differences in the relationships between mRNA levels of p53, ERCC1 and XPA. Int J Oncol 8: 313-317, 1996.

11. Pinheiro P, Gering M and Patient R: The basic helix-loop-helix transcription factor, TAL2, marks the lateral floor plate of the spinal cord in zebrafish. Gene Expr Patterns 4: 85-92, 2004.

12. Bucher K, Sofroniew MV, Pannell R, et al: The T cell oncogene Tal2 is necessary for normal development of the mouse brain. Dev Biol 227: 533-544, 2000.
13. Ferrando AA, Neuberg DS, Staunton J, et al: Gene expression signatures define novel oncogenic pathways in $\mathrm{T}$ cell acute lymphoblastic leukemia. Cancer Cell 1: 75-87, 2002.

14. Wong AST and Leung PCK: Role of endocrine and growth factors on the ovarian surface epithelium. J Obstet Gynaecol Res 33: 3-16, 2007.

15. Ahmed N, Maines-Bandiera S, Quinn MA, Unger WG, Dedhar S and Auersperg N: Molecular pathways regulating EGF-induced epithelio-mesenchymal transition in human ovarian surface epithelium. Am J Physiol Cell Physiol 290: 1532-1542, 2006.

16. Stromberg K, Johnson GR, O'Connor DM, Sorensen CM, Gullick WJ and Kannan B: Frequent immunohistochemical detection of EGF supergene family members in ovarian carcinogenesis. Int J Gynecol Pathol 13: 342-347, 1994.

17. Niikura H, Sasano H, Sato Sh and Yajima A: Expression of epidermal growth factor-related proteins and epidermal growth factor receptor in common epithelial ovarian tumors. Int $\mathrm{J}$ Gynecol Pathol 16: 60-68, 1997.

18. Cazanove O, Batut J, Scarlett G, et al: Methylation of XILF3 by Xprmt1b alters its DNA, but not RNA, binding activity. Biochemistry 47: 8350-8357, 2008.

19. Saunders LR and Barber GN: The dsRNA binding protein family: critical roles, diverse cellular functions. FASEB J 17: 961-983, 2003.

20. Vumbaca F, Phoenix KN, Rodriguez-Pinto D, Han DK and Claffey KP: Double-stranded RNA-binding protein regulates vascular endothelial growth factor mRNA stability, translation and breast cancer angiogenesis. Mol Cell Biol 28: 772-783, 2008.

21. Schumacher JJ, Dings RPM, Cosin J, Subramanian IV, Auersperg N and Ramakrishnan S: Modulation of angiogenic phenotype alters tumorigenicity in rat ovarian epithelial cells. Cancer Res 67: 3683-3690, 2007.

22. Bermudez Y, Yang H, Saunders BO, Cheng JQ, Nicosia SV and Kruk PA: VEGF- and LPA-induced telomerase in human ovarian cancer cells is Sp1-dependent. Gynecol Oncol 106: 526-537, 2007.

23. Moschos SJ and Mo YY: Role of SUMO/Ubc9 in DNA damage repair and tumorigenesis. J Mol Hist 37: 309-319, 2006.

24. Mo YY, Yu Y, Theodosiou E, Ee PL and Beck WT: A role for Ubc9 in tumorigenesis. Oncogene 24: 2677-2683, 2005.

25. Dúnnebier T, Bermejo JL, Haas S, et al: Common variants in the UBC9 gene encoding the SUMO-conjugating enzyme are associated with breast tumor grade. Int J Cancer 125: 596-602, 2009. 